\title{
Portland Cement Mortar Composite with Partial Sand Replacement by Eggshell Particles
}

\author{
Antonio Ludovico Beraldo \\ School of Agricultural Engineering, University of Campinas, Campinas, Brazil \\ Email: to.beraldo@gmail.com \\ Received 16 July 2014; revised 15 August 2014; accepted 15 September 2014 \\ Copyright (C) 2014 by author and Scientific Research Publishing Inc. \\ This work is licensed under the Creative Commons Attribution International License (CC BY). \\ http://creativecommons.org/licenses/by/4.0/

(c) (i) Open Access

\begin{abstract}
Agro-industrial activities generate a large amount of wastes. According to their specific properties, most of them can partially replace mineral aggregates, aiming to produce non-structural cement composites. In this research work, the behavior of a Portland cement mortar with partial replacement of sand by treated eggshell particles ( $0 \%$ to $66 \%$ ) has been evaluated. Firstly, chemical compatibility between eggshell particles and Portland cement was carried by hydration curves. In a second step, a mixture of cement mortar based on treated eggshell (cold water, warm water and oven-dry) was prepared. Composite hardening was monitored by an ultrasound technique. At initial ages, ultrasonic pulse velocity (UPV) along the time was sensitivity enough to detect the sand-to-eggshell ratio effect. Compressive strength at 28 days ranged from 23 to 9 MPa depending on sand to eggshell particles ratio, which indicated that the composite was suitable for non-bearing structures, mainly at rural areas.
\end{abstract}

\section{Keywords}

Non-Conventional Materials, NDE, Ultrasound, Hydration Curve, Agricultural Waste

\section{Introduction}

In the past years, several researches had been developed aiming to reduce construction costs and investigate appropriated materials, mainly the non-conventional ones. Some waste materials, such as several agro-industrial residues show potential for partially replacement of sand and coarse aggregates in mortar and concrete manufacturing. Several non-conventional aggregates (NCA) can modify the matrix's behavior by changing its normal brittle fracture to ductile fracture and at same time showing large energy dissipation (higher specific energy) 
during mechanical tests.

Despite the lower mechanical strength of these composites when compared to conventional cementitious materials, nowadays there is a specific market for non-structural lightweight materials, mainly with respect to the construction's sustainability, mainly by the possibility of employing renewable materials.

One of the advantages of NCA is associated to its availability mainly at rural areas. Among these residues, eggshell—a by-product of avian activities—is generated in a large scale, yielding 120,000 tones in Brazil [1], only at farms with 10,000 or more chickens; the waste amount is still growing if compared to that of the recent years [2].

Eggshell's structure is constituted mainly by calcium carbonate [2] and the calcium oxide content obtained by $X$-ray fluorescence spectrometer is shown to be very high ( 99.8\%) [3]. Eggshell average weight ( 5 g) depends on several parameters, such as bird's age, nutrient composition and the chicken's lineage [4] [5].

Several possibilities on employing eggshell were tested: in polymeric reinforcement [3] [6], for soil stabilization [5] and for ceramic tiles production [2]. Calcium carbonate powder was also tested as fire retardant [7].

However, only few researches had been developed evaluating inorganic matrices modified by eggshell additions to the Portland cement mortar [8] [9] or for plaster structure modifications [7].

Egg's porous structure is constituted by a membrane-type component, rich in protein [2], which remains attached to the eggshell even after crushing. However, researchers did not report any undesirable effects of natural eggshell on organic matrix [3] [6]. On the other hand, inorganic matrices are severally disturbed by NCA chemical constituents. The most important drawback of employing NCA, such as eggshell, is the possibility of their lack of compatibility with inorganic matrices. Portland cement hydration reactions normally were negatively affected by several natural compounds thus reducing the effective interaction between binder and NCA.

Searching for composite's strength enhancement, one possibility is to apply treatments to modify the eggshell behavior aiming to improve bonding with Portland cement [8]. The poor adhesion between eggshell and a polymer was also reported by [7]. According to these authors, the agglomeration of filler particles of eggshell makes the composite's strength decreased.

Earlier investigation searched the proper treatment to be applied to NCA [8] and/or choosing specific cement less affected by NCA compounds, as reported initially for Portland cement wood particles composites. Several indexes were proposed aiming to detect previously the deleterious effects of the NCA on cement paste hydration [10] [11].

However, this procedure is far from an industrial application, because cement-wood ratio is very high ( 13 times). On the other hand, conventional evaluation tests of cement-based materials require a very large interval of time ( 28 days) to be applied. So, a quick and non-destructive evaluation (NDE), as ultrasound, allows detecting negative interactions between cement and NCA. In most of the cases, an unexpected ultrasonic pulse velocity (UPV) is related to the poor matrix-to-NCA interaction. This strategy permits anticipating the time expended for the material's property evaluation. A comprehensive study about UPV application on concrete properties evaluation was recently published [12].

Mortar's hardening along the time (hours or days) can be surveyed aiming to obtain parameters, explaining reaction's kinetic. A mathematical model was proposed by [13]:

$$
V_{i}=v_{\max }[1-\exp (A-B i)]
$$

where

$V_{i}=$ ultrasonic pulse velocity (UPV) at age "I";

$V_{\max }=$ maximum empirical UPV value;

$i=$ specimen's age (days);

$A$ and $B=$ coefficients obtained by linear regression.

The coefficient $A$ explains the initial material's hardening, i.e. if when UPV measurement process begins there was yet a solid structure allowing the wave propagation. In the other hand, $B$ coefficient is related to the chemical reaction's speed, denoting its effectiveness. The higher the $B$ value is, the faster the reaction will be.

Relationships between compressive strength of Portland cement based materials and non-destructive parameters as UPV and dynamic modulus of elasticity (Ed) were reported in literature [8] [14]. The effect of silica fume, fly-ash and blast furnace slag on compressive strength of cement-based materials was investigated by UPV. A mathematical model was proposed by [14]: 


$$
\mathrm{CS}=\mathrm{A} \exp (\mathrm{BUPV})
$$

where

$\mathrm{CS}=$ compressive strength (MPa);

$\mathrm{UPV}=$ ultrasonic pulse velocity $\left(\mathrm{m} \cdot \mathrm{s}^{-1}\right)$;

$A$ and $B=$ empirical coefficients obtained by regression.

Another model was proposed by [8] for eggshell-cement composite:

$$
\mathrm{CS}=\mathrm{A}(\mathrm{UPV})^{B}
$$

Compressive strength of several materials depends on theirs densities, which also influences the UPV magnitude. Theoretically the interaction between these properties, explained by the dynamic modulus of elasticity (Ed), is the most useful parameter to predict the compressive strength. Ed is calculated by:

$$
\mathrm{Ed}=\rho \cdot(\mathrm{UPV})^{2} \cdot 10^{-9}
$$

where:

$\mathrm{Ed}=$ dynamic modulus of elasticity (GPa);

$\rho=$ bulk density $\left(\mathrm{kg} \cdot \mathrm{m}^{-3}\right)$.

The aim of this research work was to evaluate, by ultrasound and by compression tests, the Portland cement mortar behavior by partially replacing sand by eggshell treated particles.

\section{Materials and Methods}

Particles preparation: Eggshell was collected from laying birds, 3 years aged, at a farm located in Sao Paulo State, Brazil. Eggshell was disintegrated in a hammer-mill and particles passing at $2.40 \mathrm{~mm}$ sieve opening were selected. Compared to the sand grain size, eggshell was coarser. Bulk density was near of $1.0 \mathrm{~g} \cdot \mathrm{cm}^{-3}$.

Eggshell particles treatments: washing-up in cold water $\left(24 \mathrm{~h}\right.$ at $\left.25^{\circ} \mathrm{C}\right)$, washing-up in warm water $(2 \mathrm{~h}$ at $\left.80^{\circ} \mathrm{C}\right)$ and oven-dry $\left(24 \mathrm{~h}\right.$ at $\left.60^{\circ} \mathrm{C}\right)$.

Cement type: Mortar was compound of a high initial strength Portland cement (CP-V-ARI—Brazilian Association of Technical Standard ABNT-NBR 5733 [15] and a medium size sand.

Hydration curve: Mortars of Portland cement, sand and eggshell particles were placed in a pseudo-adiabatic calorimeter. Cement mass was $50 \mathrm{~g}$; sand mass was $150 \mathrm{~g}$ (reference mortar). Sand and treated eggshell particles mass, in grams, were, respectively, T1-150/0; T2-125/25; T3-150/50; T4-75/75; T5-50/100 and T6-25/125. For all mixtures, water mass was kept constant (25 g). Mixture's temperature was collected every 15 seconds by means a thermocouple type $\mathrm{J}$ connected to a data acquisition system, featuring an interface to a computer.

Specimens: Brazilian Standard NBR 7215 [16] for Portland cement mortar was partially modified. Three cylindrical specimens (50 mm diameter and $100 \mathrm{~mm}$ height) were produced by combining treatments applied to the eggshell particles and the sand-to-treated eggshell particles mass ratios of 3.0/0.00 (reference), 2.5/0.5, 2.0/1.0, 1.5/1.5 and 1.0/2.0. Mortar was carefully mixed to achieve material homogeneity and then it was placed into plastic molds. After $24 \mathrm{~h}$, specimens were de-molded and kept in a controlled room during 28 days.

Non-destructive testing by ultrasound: Ultrasonic pulse velocity (UPV) across the specimens was daily evaluated by means an ultrasonic tester device Steinkamp, model BP7, with exponential transducers section

Compressive strength: At 28 days, specimens were prepared according to Brazilian standard NBR 7215 and submitted to a compression test in an EMIC device, model 30,000, adopting $10 \mathrm{~mm} \cdot \mathrm{min}^{-1}$ of displacement speed. Analysis of variance (ANOVA) was applied aiming to evaluate the influence of the treatments applied to eggshell particles and the ratios sand-to-eggshell. Averages were compared by Tukey’s test at 95\% probability level.

\section{Results}

\section{a) Hydration curves}

Figure 1 shows the hydration curves for mortars of Portland cement, sand and eggshell particles treated in warm water. Time spends to reach the maximum temperature for the mixtures ranged from 6.5 hours (T1 reference ones) to 9.75 hours (T6). The higher the sand-to-eggshell replacement is, the higher the time of temperature peak will be. Except for T5 (50/100), mixture's temperature were close to $60^{\circ} \mathrm{C}$. However, it must be considered 
that the mixture's volume was different for each case. Considering that bulk density of sand and of eggshell was 1.5 and $1.0 \mathrm{~g} \cdot \mathrm{cm}^{-3}$, respectively, volume mixture increases from $100 \mathrm{~cm}^{3}$ (150/0) to $142 \mathrm{~cm}^{3}$ (25/125). In addition, also system insulation cannot be considered as effective.

b) Ultrasonic pulse velocity-UPV

Table 1 shows the coefficients of the mathematical model proposed in Equation (1). For small sand-to-eggshell ratio (2.5/0.5), for all of the treatments applied, UPV is similar to those from reference ones $\left(3.48 \mathrm{~km} \cdot \mathrm{s}^{-1}\right)$. The lower sand-to-eggshell replacement, the smaller the UPV maximum value, denotes clearly the changes occurred on the composite's structure.

Treatment's effect seems to be less important on UPV magnitude, but there is a tendency that warm water and oven-dry treatments applied to the eggshell to produce a positive effect. For sand-to-eggshell ratio1.0/2.0, the maximum UPV (2.58 and $2.62 \mathrm{~km} \cdot \mathrm{s}^{-1}$, respectively) is higher when compared to the cold treatment (2.18 $\mathrm{km} \cdot \mathrm{s}^{-1}$ ). The same tendency is observed for the ratios 1.0/2.0 and 1.5/1.5.

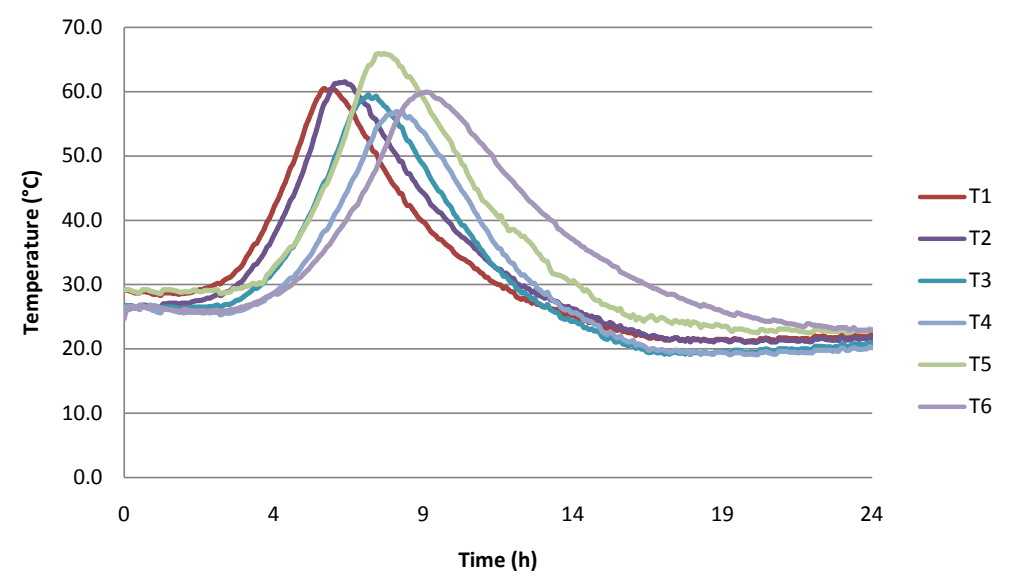

Figure 1. Hydration curves for the Portland cement mortars according to the sand-to-eggshell mass (in g). T1-150/0 (reference); T2-125/25; T3-100/50; T4-75/75; T5-50/100 and T6-25/125.

Table 1. Coefficients of a mathematical model $v_{\mathrm{i}}=v_{\max }(1-(A-B i))$, according to the treatment applied to the eggshell particles and the ratio sand-to-eggshell particles.

\begin{tabular}{|c|c|c|c|c|c|c|}
\hline Treatment & Ratio & $3.0 / 0.0$ & $2.5 / 0.5$ & 2.0/1.0 & $1.5 / 1.5$ & $1.0 / 2.0$ \\
\hline \multirow{4}{*}{ Cold } & A & -0.598 & -0.242 & -0.403 & -0.400 & -0.334 \\
\hline & $B$ & -0.646 & -1.981 & -1.029 & -0.792 & -1.026 \\
\hline & $r^{2}$ & 0.98 & 0.83 & 0.96 & 0.94 & 0.92 \\
\hline & $v_{\max }$ & 3.48 & 3.53 & 3.05 & 2.74 & 2.18 \\
\hline \multirow{4}{*}{ Warm } & A & -0.598 & -0.472 & -0.227 & -0.224 & -0.223 \\
\hline & $B$ & -0.646 & -1.188 & -1.416 & -1.448 & -1.460 \\
\hline & $r^{2}$ & 0.98 & 0.80 & 0.96 & 0.96 & 0.96 \\
\hline & $v_{\max }$ & 3.48 & 3.54 & 3.46 & 2.92 & 2.58 \\
\hline \multirow{4}{*}{ Oven-dry } & A & -0.598 & -0.420 & -0.389 & -0.363 & -0.370 \\
\hline & $B$ & -0.646 & -0.958 & -0.922 & -0.842 & -0.784 \\
\hline & $r^{2}$ & 0.98 & 0.96 & 0.92 & 0.94 & 0.94 \\
\hline & $v_{\max }$ & 3.48 & 3.59 & 3.27 & 2.81 & 2.62 \\
\hline
\end{tabular}


With respect to the coefficient A, in all of the combined cases, the UPV corresponding to the reference specimen (without eggshell particles) was higher, denoting that its kinetic reaction was faster. In the other hand, coefficient B for the reference ones was smaller denoting that the UPV acceleration was faster. For higher sand-to-eggshell particles ratios and for a warm water treatment, B value was almost constant. For the others cases, there was not a clear tendency of the combination of the treatment type and the ratio sand-to-eggshell particles on B value.

Figure 2 to Figure 4 show the UPV curve's behavior, according to the specimen's age, combining the treatments

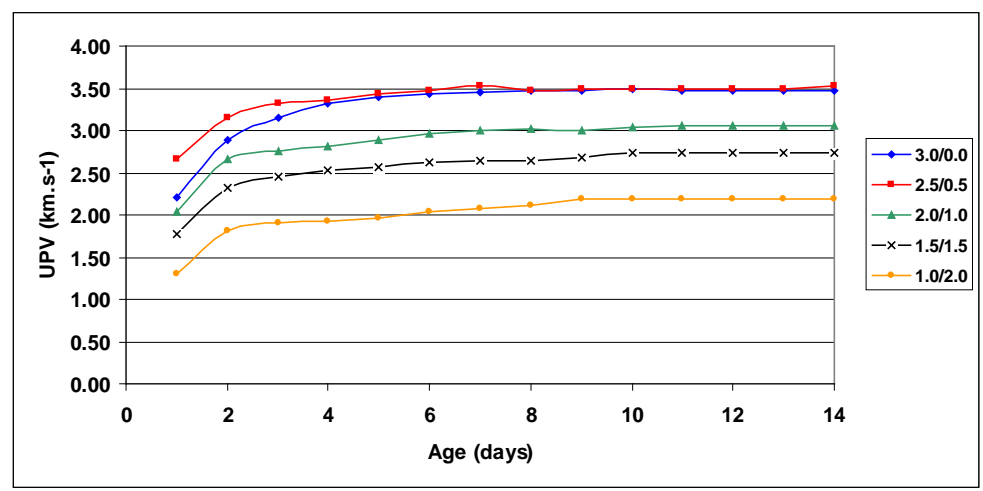

Figure 2. Cold water treatment on UPV across the age, according to the sand/ eggshell particles ratio.

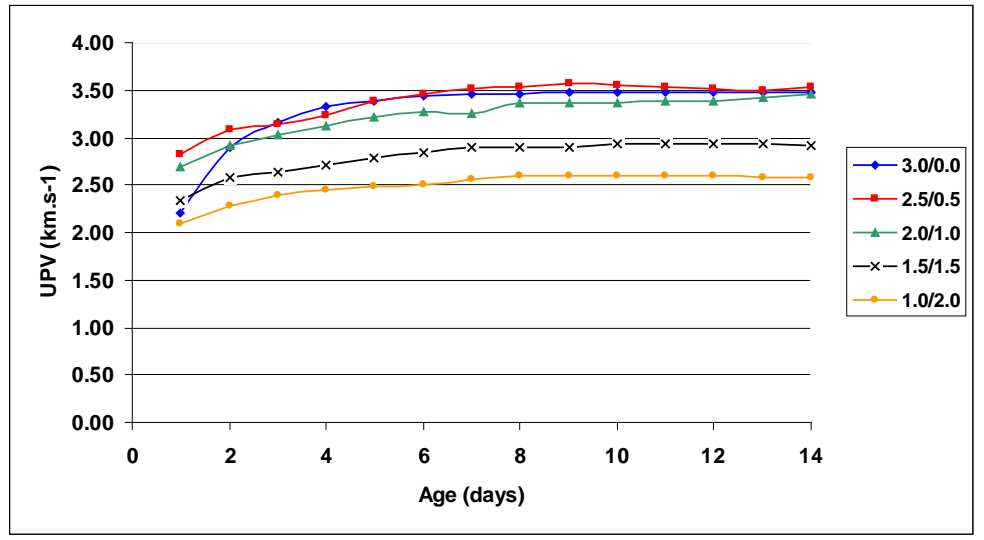

Figure 3. Warm water treatment on UPV across the age, according to the sand/eggshell particles ratio.

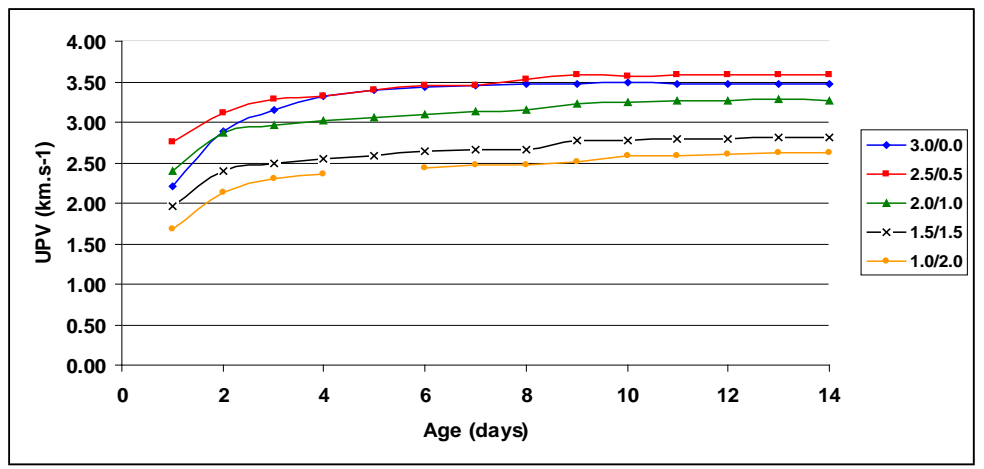

Figure 4. Oven-dry treatment on UPV across the age, according to the sand/ eggshell particles ratio. 
applied to the eggshell particles and the sand-to-eggshell particles ratios. After 7 days, UPV's values remain almost constant in all of the cases, denoting that this method is not sensitive enough to detect subsequently matrix modification as provoked by carbonation effect.

Despite differences observed at earlier ages, for all of the treatments, after few days UPV corresponding to the low sand-to-eggshell particles replacement (2.5/0.5) was similar to those from the reference ones (3.0/0.0). Ultrasound method was clearly capable of to separate the effect of the sand-to-eggshell particlesratios on UPV behavior for all of the treatments. This method was sufficient enough to detecting the curve's behavior at the first age, allowing choosing the most suitable combination of sand-to-eggshell particles ratio and the treatment applied to the eggshell particles. In other words, it is expected that even at the first day, higher UPV better the results expected in a destructive test.

c) Compressive strength

As pointed by ultrasound, composite's compressive strength was lower than those of the mortar reference ( $\sim 34 \mathrm{MPa}$ ). Four combinations of sand-to-eggshell ratio and treatment applied to the eggshell particles allow compressive strength of $20 \mathrm{MPa}$ or higher (Figure 5).

Table 2 shows the Analysis of Variance (ANOVA). Only sand-to-eggshell particles ratio influences significantly the composite's compressive strength. There is also a tendency of an interaction between sand-to-eggshell particles ratio and the type of treatment applied to eggshell particles.

A mathematical model explaining the relationship between sand-to-eggshell particles ratio and compressive strength was proposed:

$$
\text { Compressive strength }=25.56-4.35 \times \text { Ratio }
$$

where, ratios were:

1-2.5/0.5; 2-2.0/1.0; 3-1.5/1.5 and 4-1.0/2.0, for sand/eggshell particles respectively.

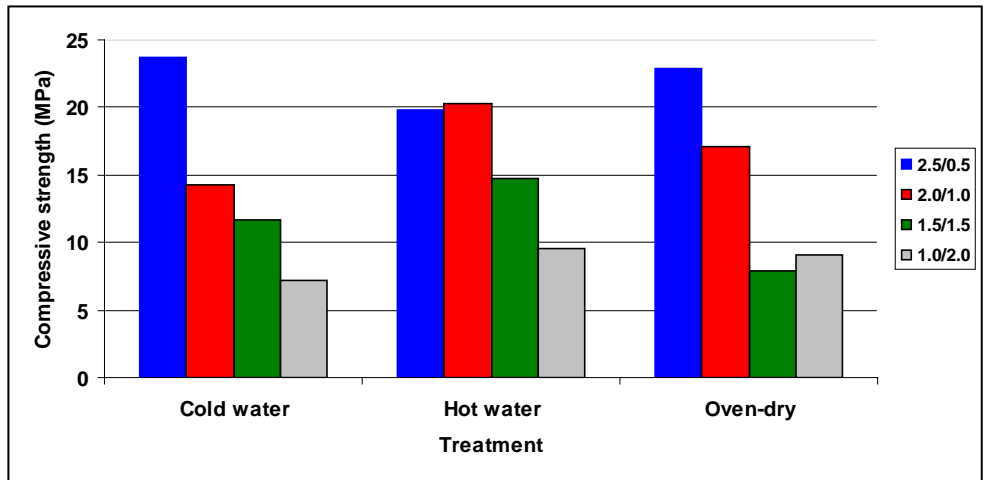

Figure 5. Treatment's effect on composite's compressive strength, according to the sand/eggshell particles ratio.

Table 2. Analysis of variance for compressive strength-type III Sums of squares.

\begin{tabular}{cccccc}
\hline Source & Sum of Squares & Df & Mean Square & F-Ratio & P-Value \\
\hline MAIN EFFECTS & & & & & \\
A:Treatment & 17.7823 & 2 & 8.89117 & 1.33 & 0.2842 \\
B:Sand/eggshell ratio & 856.731 & 3 & 285.577 & 42.60 & 0.0000 \\
INTERACTIONS & & & & 2.19 \\
AB & 88.0656 & 6 & 14.6776 & 6.70371 & \\
RESIDUAL & 160.889 & 24 & & \\
TOTAL (CORRECTED) & 1123.47 & 35 & &
\end{tabular}

All F-ratios are based on the residual mean square error. 
According to this model, even for the higher sand-to-eggshell ratio (1.0/2.0), composite's compressive strength is $\sim 9 \mathrm{MPa}$, thus allowing its application for non-bearing hollow blocks manufacturing or for ornamental purposes. The contrast between the cement and eggshell colors produces an aesthetic aspect (Figure 6).

Correlation between compressive strength and UPV

According to Equations (2) and (3), mathematical models were tested aiming to correlate compressive strength with UPV. Specimens grouped by sand-to-eggshell particles ratios (including all of treatments applied to eggshell particles) showed different behaviors for some sand-to-eggshell particles ratio, both models were not conclusive ( $r^{2}$ is smaller than 0.40 ). However, when sand-to-eggshell particles ratios were grouped, mathematical models exhibited better performance (Table 3). Experimental data were closer to those obtained for both models predictions (Figure 7).

In the other hand, except for the sand-to-eggshell particles ratio 1.0/2.0, equation (4) did not explain the dependence between compressive strength and dynamic modulus of elasticity.

Standard deviation of compressive strength was higher than those of UPV denoting the influence of others factors on the composite's performance, as the manufacturing process or an inadequate bonding between cement mortar and eggshell particles.

Micro pores (Figure 8(a)) and interface region (Figure 8(b)) was detected on composite by SEM. Both are important to enhance the bonding of eggshell particles with cement mortar. Hydration's products as portlandite and ettringite were observed at interface region, denoting theirs interactions with eggshell surface. A porous zone remains at the border of the eggshell particles and probably is responsible for its lack of bonding with cement mortar.

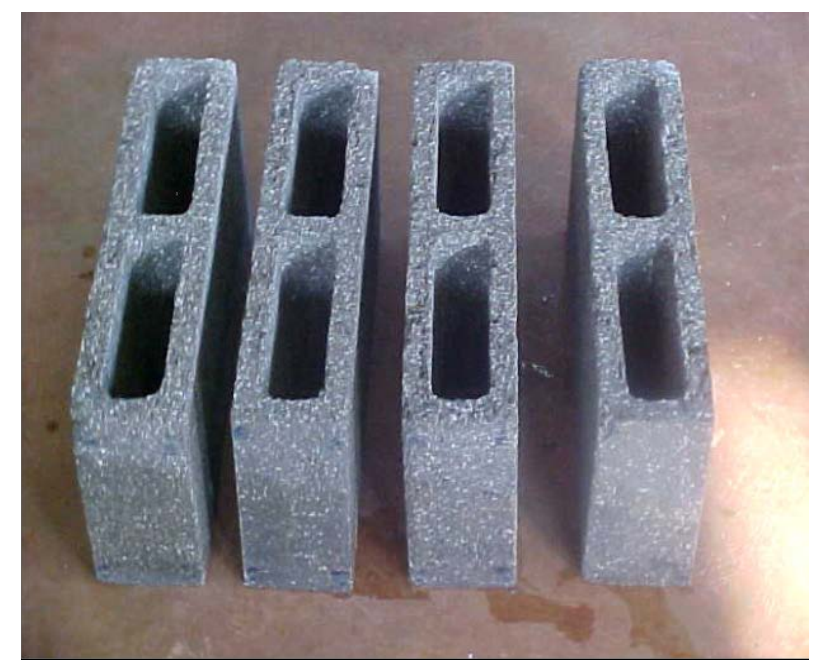

Figure 6. Application of Portland cement mortar-eggshell particles.

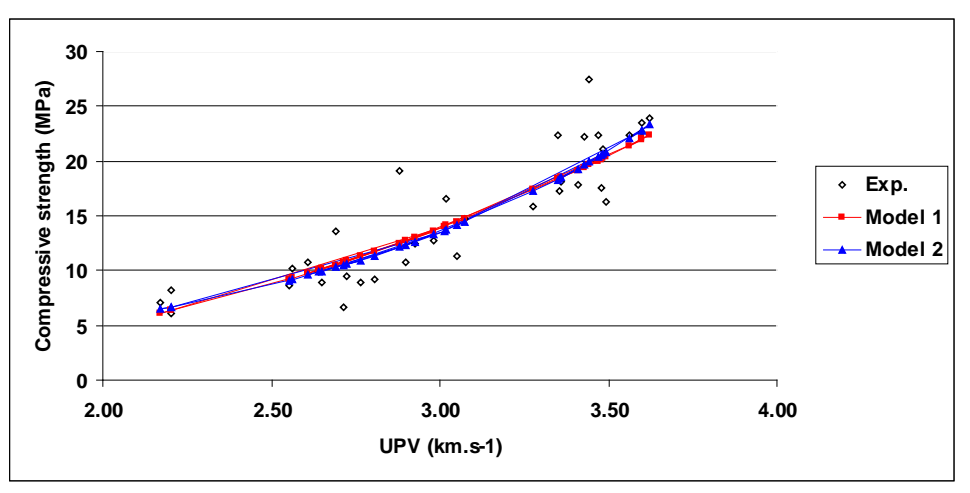

Figure 7. Experimental and theoretical compressive strength of Portland cement mortar-eggshell particles. 


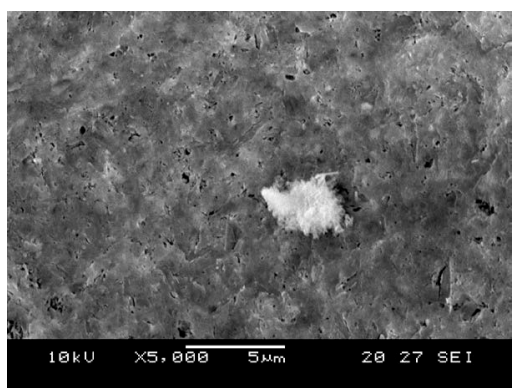

(a)

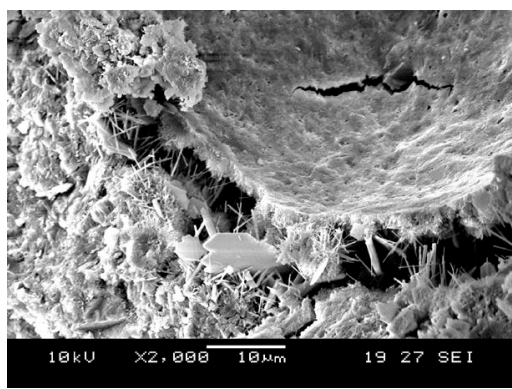

(b)

Figure 8. (a) Eggshell micro pores; ( b) Eggshell cement composite bonding.

Table 3. Mathematical models for compressive strength vs UPV.

\begin{tabular}{ccccccc} 
& Model 1 & $\mathrm{CS}=\mathrm{Av}^{\mathrm{B}}$ & \multicolumn{3}{c}{ Model 2 } & \multicolumn{2}{c}{$\mathrm{CS}=\mathrm{Ae}^{\mathrm{Bx}}$} \\
\hline Ratio & $\mathrm{A}$ & $\mathrm{B}$ & $\mathrm{r}^{2}$ & $\mathrm{~A}$ & $\mathrm{~B}$ & - \\
$2.5 / 0.5$ & - & - & - & - & 0.2639 & 0.99 \\
$2.0 / 1.0$ & 0.43 & 0.8536 & 0.99 & 0.4988 & - & - \\
$1.5 / 1.5$ & - & - & - & - & 0.5355 & 0.61 \\
1.0 & 2.5715 & 1.3147 & 0.62 & 2.237 & 0.8784 & 0.82 \\
All ratios & 0.8544 & 2.5363 & 0.81 & 0.9664 & & \\
\hline
\end{tabular}

\section{Conclusions}

Non-destructive test by ultrasound was capable of survey composites hardening according the time.

Composite performance depended on sand-to-eggshell ratios, but not from the treatment applied to the eggshell.

Mathematical models allowed to predict composite's compressive strength by ultrasonic pulse velocity.

Portland cement composites from sand partial replacement by treated eggshell particles showed potentialities to be applied for non-structural purposes mainly at rural areas.

\section{References}

[1] Brazilian Institute of Geography and Statistics-IBGE. http://www.ibge.gov.br

[2] Freire, M.N. and Holanda, J.N.F. (2006) Characterization of Avian Eggshell Waste Aiming Its Use in a Ceramic Wall Tile Paste. Cerâmica, 52, 240-244. http://dx.doi.org/10.1590/S0366-69132006000400004

[3] Shuhadah, S. and Supri, A.G. (2009) LDPE-Isophthalic Acid-Modified Egg Shell Powder Composites (LDPE/ESPI). Journal of Physical Science, 20, 87-98.

[4] Da Silva, J.H.V. and Dos Santos, V.J. (2000) Calcium Carbonate Effect on the Eggshell Quality. Revista Brasileira de Zootecnia, 29, 1440-1445. (In Portuguese)

[5] Amu, O.O. and Salami, B.A. (2010) Effect of Common Salt on Some Engineering Properties of Eggshell Stabilized Lateritic Soil. ARPN Journal of Engineering and Applied Sciences, 5, 64-73.

[6] Hussein, A.A., Salim, R.D. and Sultan, A.A. (2011) Water Absorption and Mechanical Properties of High-Density Polyethylene/Egg Shell Composite. Journal of Basrah Researches (Sciences), 37, 36-42.

[7] Huang, K.T., Liang, H.H. and Hung, M.J. (2010) Improvement in Fire Prevention Performance of Cork-Gypsum Decorative Materials by Applying Porous Waste. International Journal of the Physical Sciences, 5, 2038-2044.

[8] Nagumo, C.H. and Beraldo, A.L. (2004) Eggshell and Portland Cement Mortar. Annals of ICTR-International Conference on Waste Treatment, Florianópolis, 2004, 2088-2097. (In Portuguese)

[9] Nagumo, C.H. and Beraldo, A.L. (2005) Composite from Eggshell, Pinus Caribaea Waste and Portland Cement Mortar. Annals of XXIV CONBEA-Agricultural Engineering Congress, Canoas, 2005, 4 p. (In Portuguese)

[10] Sandermann, W., Preusser, H.J. and Schiens, W. (1960) The Effect of Wood Extractives on the Setting of CementBonded Wood Materials. Holzforschung, 14, 70-77. http://dx.doi.org/10.1515/hfsg.1960.14.3.70 
[11] Weatherwax, R.C. and Tarkow, H. (1964) Effect of Wood on Setting of Portland Cement. Forest Products Journal, 14, 567-568.

[12] Panzera, T.H., Christophoro, A.L., Cota, F.P., Borges, P.H.R. and Bowen, C.R. (2011) Chapter 17: Ultrasonic Pulse Velocity Evaluation of Cementitious Materials. In: Těšinova, P., Ed., Materials ScienceComposite Materials Advances in Composite Materials-Analysis of Natural and Man-Made Materials, Intech, Croácia, 411-436. http://dx.doi.org/10.5772/17167

[13] Beraldo, A.L. (1999) Ultrasonic Speed Wave: Cure Type Influence on Wood-Cement Composite Compression Strength. NDTISS'99-International Symposium on Nondestructive Testing Contribution to the Infrastructure Safety Systems in 21st Century, ABENDE-Brazilian Association of Non Destructive Testing, 1, 86-90.

[14] Gül, R., Demirboğa, R. and Güvercin, T. (2006) Compressive Strength and Ultrasound Pulse Velocity of Mineral Admixtured Mortar. Indian Journal of Engineering \& Materials Sciences, 13, 18-24.

[15] Brazilian Standard Technical Norms, ABNT (1991) NBR 5733. High Initial Strength Portland Cement. Specifications, Rio de Janeiro, 5 p. (In Portuguese)

[16] Brazilian Standard Technical Norms, ABNT (1996) NBR 7215. Portland Cement: Compressive Strength Determination. Test Method, Rio de Janeiro, 8 p. (In Portuguese) 
Scientific Research Publishing (SCIRP) is one of the largest Open Access journal publishers. It is currently publishing more than 200 open access, online, peer-reviewed journals covering a wide range of academic disciplines. SCIRP serves the worldwide academic communities and contributes to the progress and application of science with its publication.

Other selected journals from SCIRP are listed as below. Submit your manuscript to us via either submit@scirp.org or Online Submission Portal.
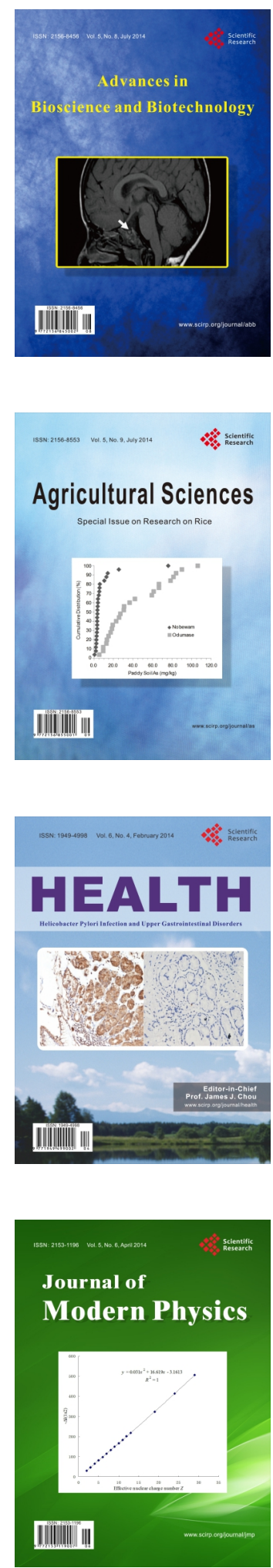
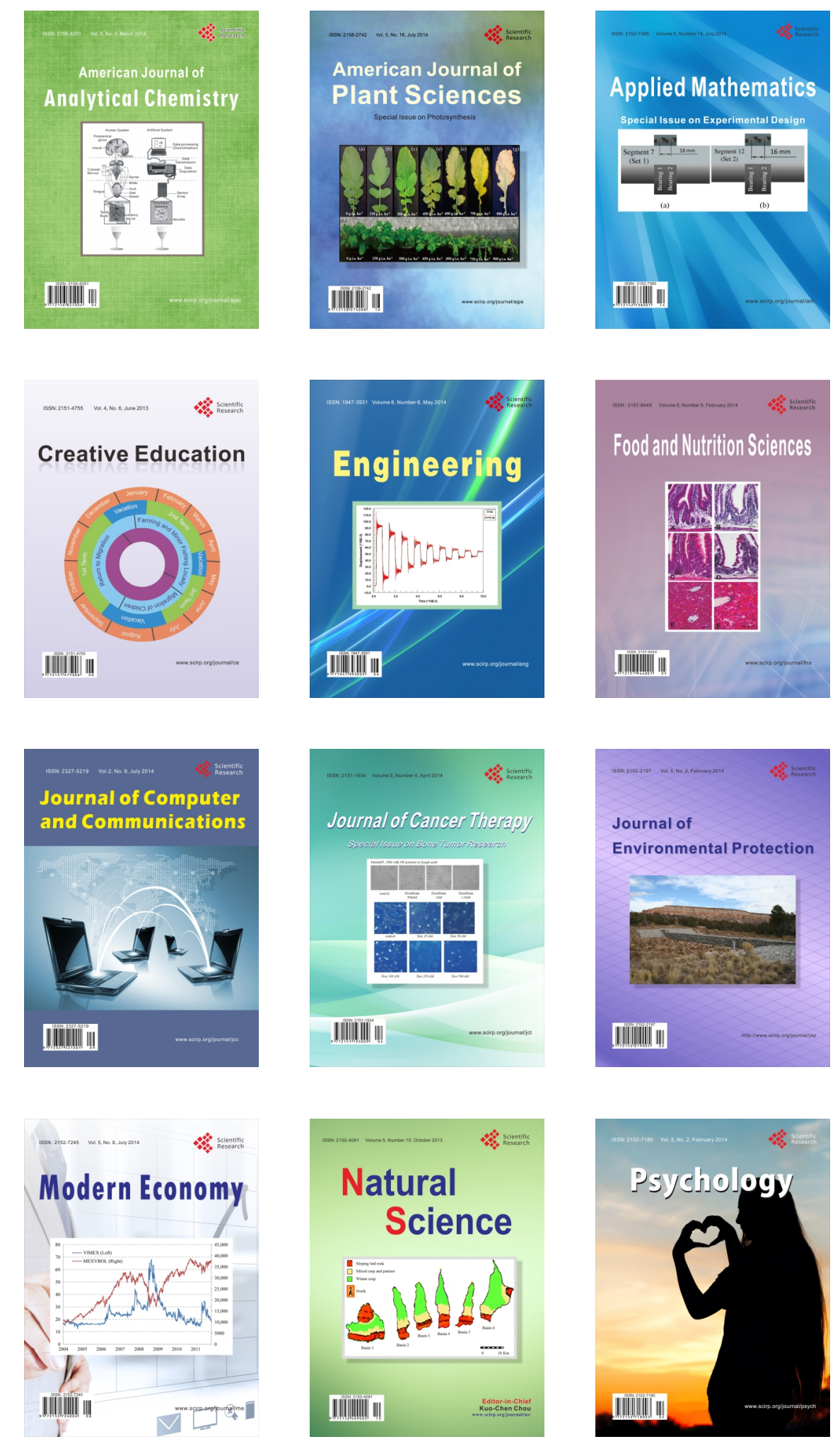